\title{
Experiences and Psychological Wellbeing Outcomes Associated with Bullying in Treatment-Seeking Transgender and Gender-Diverse Youth
}

\author{
Gemma L. Witcomb, PhD, ${ }^{1}$ Laurence Claes, $\mathrm{PhD},{ }^{2}$ Walter Pierre Bouman, MD, PhD, ${ }^{3}$ Elena Nixon, $\mathrm{PhD},{ }^{4}$ \\ Joz Motmans, $\mathrm{PhD},{ }^{5}$ and Jon Arcelus, MD, $\mathrm{PhD}^{3,4}$
}

\begin{abstract}
Purpose: Bullying in the adult transgender population is well documented, but less is known about bullying in transgender and gender-diverse (TGD) youth. Studies have begun to explore experiences of bullying and the associated psychological distress in TGD youth; however, they often fail to distinguish among the separate groups within LGBT samples. This study sought to explore the prevalence, nature, and outcomes of bullying in TGD youth attending a transgender health service in the United Kingdom, taking into account birth-assigned sex and out and social transition status.

Methods: Before their first appointment at a specialist gender clinic, participants completed a brief sociodemographic questionnaire, a questionnaire assessing experiences and outcomes of bullying, and a clinically validated measure of anxiety and depression (Hospital Anxiety and Depression Scale).

Results: A total of 274 TGD people aged 16-25 years participated in the study. The majority of participants $(86.5 \%)$ reported having experienced bullying, predominantly in school. Bullying was more prevalent in birth-assigned females and in out individuals, and commonly consisted of homophobic/transphobic (particularly in socially transitioned individuals) or appearance-related (particularly in out individuals) name calling. Individuals who reported having experienced bullying showed greater anxiety symptomology and also self-reported anxiety, depression, and low self-esteem as effects of bullying. Birth-assigned females also reported greater effects on family relationships and social life.

Conclusion: These findings indicate very high levels of bullying within the young TGD population attending a transgender health service in the United Kingdom, which affects wellbeing significantly. More intervention work and education need to be introduced in schools to reduce bullying.
\end{abstract}

Keywords: adolescence, gender diverse, gender identity, mental health, minority stress, transgender

\section{Introduction}

$\mathbf{T}$ HE NUMBER OF INDIVIDUALS who report their gender identity as not being congruent with their sex assigned at birth and who identify as transgender has increased rapidly in recent years. ${ }^{1-4}$ Some transgender people wish to undergo gender-affirming medical interventions to express their experienced gender, whereas others choose not to do so. ${ }^{5}$ Those who wish to undergo these interventions will need to access transgender health services. ${ }^{6}$ Research with transgender people accessing clinical services has found that they often pres- ent with elevated levels of mental health problems compared with the general population, most notably anxiety and depression, ${ }^{7-10}$ low self-esteem, ${ }^{11}$ self-harm, ${ }^{12-14}$ and disordered eating and poor body image. ${ }^{15,16}$

For example, research has found that those who identify as nonbinary present with higher levels of mental health problems than binary trans people, ${ }^{17,18}$ and up to $46 \%$ of young trans people acknowledge self-harming, ${ }^{14}$ making this group of transgender people most at risk. ${ }^{19}$ This is perhaps not surprising, given that adolescence is considered to be a critical period for identity development, and the formation of gender

\footnotetext{
${ }^{1}$ School of Sport, Exercise and Health Sciences, Loughborough University, Loughborough, United Kingdom.

${ }^{2}$ Faculty of Psychology and Educational Sciences, KU Leuven, Leuven, Belgium.

${ }^{3}$ The Nottingham Centre for Transgender Health, Nottingham, United Kingdom.

${ }^{4}$ Faculty of Medicine and Health Sciences, Institute of Mental Health, University of Nottingham, Nottingham, United Kingdom.

${ }^{5}$ Centre for Sexology and Gender, Ghent University Hospital, Ghent, Belgium.
} 
identity is a vital part of this process. ${ }^{20,21}$ The development of identity is also closely linked to the sense of belonging, which is an important part of self-esteem development. Notably, transgender youth report difficulties in engaging in everyday activities with their peers, such as sports, ${ }^{22-24}$ which can affect their sense of belonging to their peer group and consequently their self-esteem. ${ }^{25}$

Research within the general population has found that social connectedness is key in building self-esteem. ${ }^{26,27}$ One way in which social connectedness and self-esteem can be affected negatively is through bullying. ${ }^{28,29}$ Bullying is a repeatedly unwanted aggressive (physical or psychological) behavior that involves a real or perceived power imbalance and can be verbal (e.g., name calling), social (e.g., leaving someone out on purpose), physical (e.g., hitting/spitting), or sexual (e.g., unwanted sexual comments or attention). ${ }^{30}$ Bullying can also take place remotely, in cyber space, through social media. ${ }^{31}$ Young people who are bullied by peers exhibit a lower sense of belonging to their school community and higher levels of depressive symptomatology, ${ }^{25}$ as well as symptoms of post-traumatic stress disorder. ${ }^{32}$ Overall, experiences of bullying in childhood are associated with poor mental, physical, and cognitive health outcomes, which are pervasive and track into adulthood. ${ }^{33}$ Many of the mental health problems ${ }^{14,34-36}$ and the high rates of school nonattendance ${ }^{37-39}$ found among transgender people may be explained by the experience of bullying.

Many studies have reported the high levels of discrimination that are experienced in the transgender population. ${ }^{40,41}$ However, most studies have focused on adults and, therefore, the influence of bullying during the vital developmental period of adolescence/young adulthood has not been fully explored in transgender youth. This could be for a number of reasons. First, until recently, because of the lack of visibility and acceptance of transgender people in society, many people hid their gender identity until adulthood and, therefore, did not experience bullying in their youth, or if they did, their experiences would only be reported retrospectively. Indeed, it has been found that older transgender people experience less internalized transnegativity and less psychological distress than younger transgender people,${ }^{42}$ which may be related to less experience of bullying. Second, studies including young transgender people tend to do so under the LGBT umbrella, with the majority of participants identifying as lesbian, gay, or bisexual (LGB) rather than transgender. As sexual orientation identity and gender identity are very different, the nature and effects of bullying are likely to be different and thus not described reliably. ${ }^{43}$ Recent studies have begun to explore the experiences of transgender youth separately from their LGB peers. ${ }^{35,44}$ However, these studies have relied heavily on the use of online surveys and, therefore, may have attracted a biased sample; that is, those who have experienced bullying being more likely to engage with the survey than those who have not experienced bullying.

In light of the limited evidence on the nature and possible effects of bullying in transgender youth, this study aimed to explore experiences of bullying in a homogeneous sample of treatment-seeking young transgender and gender-diverse (TGD) people presenting for their first assessment at a national transgender health service. Experiences and outcomes of bullying and the association with current psychological wellbeing (depression and anxiety) were investigated, taking into account birth-assigned sex and out and transition status. As bulling can take many forms and, importantly, many transgender people may initially come out as lesbian, gay, or bisexual, the study explored multiple aspects of bullying and was not limited to transphobic bullying only.

In summary, we hypothesized that TGD youth would be more likely to report having experienced bullying than not having experienced bullying, and that reporting experiences of bullying would be associated with greater anxiety and depression symptomology and other negative effects on wellbeing. We also hypothesized that bullying may differ based on visibility (out and/or social transition status) as people may experience more bullying once others are more aware of their transgender identity. Regarding sex assigned at birth, as society remains largely heteronormative and less accepting of feminine boys compared with masculine girls,${ }^{45,46}$ we hypothesized that bullying may be higher in individuals assigned male at birth.

\section{Methods}

\section{Participants}

In line with the age range used in previous studies with transgender youth, ${ }^{14,17,18}$ youth were defined as those aged 16-25 years. This is broadly consistent with the United Nations definition of youth being of ages 15-24 years but acknowledges that this may differ depending on context. ${ }^{47}$ All individuals aged 16 to 25 years who were offered an appointment at a national transgender health service in the United Kingdom between November 2014 and December 2016 were invited to participate. The clinic is one of the larger transgender health services in Europe and receives $>1000$ referrals a year of people aged 16 years and older $(>50 \%$ are young people aged $16-25$ years).

\section{Procedure}

Before their first appointment, patients referred to the clinic were sent (through mail) an invitation to participate in the study, which included an information sheet, a consent form, and the questionnaires (see Measures section). The questionnaires could be completed in the individual's own time and were returned either by post or brought to the first appointment. No questions were labeled as mandatory and questions could be skipped. This study was part of a longitudinal study looking at the clinical correlates and outcomes of the treatment pathways for transgender people attending a national clinic in the United Kingdom. For their data to be included in this study, all participants had to sign the consent form. If they did not consent, the information was not used for research. There were no additional steps to encourage participation beyond this and no incentives were offered.

The study received ethical approval from the National Health Service (NHS) Research Ethics Committee and the Research and Development Department of the Nottinghamshire Healthcare NHS Foundation Trust (REC: 14/ EM/0092) in line with Health Research Authority guidance, which included approval for individuals aged 16 years and older to sign, giving their consent without the need for additional parental consent. 


\section{Measures}

Demographics. This brief questionnaire required participants to indicate their age, birth-assigned sex, and identified gender. The response options for this latter question were developed in consultation with transgender people as part of a study funded by the World Health Organization ${ }^{48,49}$ and consisted of six options: (1) I identify as a man (including with a trans history); (2) I identify as a woman (including with a trans history); (3) I identify partly as a man and partly as a woman; (4) I identify neither as a man nor as a woman; (5) I don't know what my gender identity is (yet) or I am questioning my gender identity; (6) Other (please specify). Participants were also asked to indicate, if applicable, the age at which they came out and the age at which they socially transitioned. These were self-defined and participants were not given any definition. The participants were also asked to identify their ethnic origin and the following response options were given: White, Black Caribbean, Black African, Black Other, Indian, Pakistani, Bangladeshi, Chinese, Other ethnic group (please specify).

The Hospital Anxiety and Depression Scale ${ }^{50}$. This is a 14-item self-report screening scale developed to indicate the possible presence of anxiety and depression states. It consists of two subscales, each with seven items. An example of an anxiety question is "I feel tense or "wound up", and an example of a depression question is "I feel as if I am slowed down." Participants are asked to indicate, using a 4-point Likert scale denoting agreement or disagreement, how often they have felt that way during the preceding week. A score of 0-7 on either scale is regarded as being in the normal range (no symptoms), a score of $8-10$ is suggestive of the presence of a disorder (possible symptoms), and a score of 11 or higher indicates the probable presence of a disorder (symptoms), with the maximum subscale score being 21. The Hospital Anxiety and Depression Scale (HADS) has been found to perform well in assessing the symptom severity and caseness of disorders in both patients and the adult general population ${ }^{51}$ and adolescents, ${ }^{52}$ and has been used previously in the transgender population., 8,53 Cronbach's alpha coefficients were very good for the measure of anxiety $(\alpha=0.823)$ and good for the measure of depression $(\alpha=0.742)$.

The Transgender Bullying Questionnaire. This descriptive questionnaire was developed specifically for the purposes of this study. The aim of the questionnaire was to collect information regarding reported experiences of bullying and the type and nature of bullying behavior. Questions were developed after reviewing existing literature by different organizations (e.g., the UK's National Society for the Prevention of Cruelty to Children [NSPCC]).

The questionnaire consists of nine items. Item 1 asks participants to indicate whether they have ever experienced bullying (yes/no). This is self-defined. If yes, eight questions follow that explore the bullying in more detail. Specifically, participants are asked to indicate when bullying occurred (in the past 12 months, 1-2 years ago, or 2 or more years ago; item 2) and where bullying occurred (school, college, work, outside place, home, or online; item 3). Item 4 then asks how bullying occurred, with response options of (a) physical (when someone pushes you, hits you, or harms you in any way physically), (b) name calling (being verbally called names), (c) social (being excluded by others), cyber (being bullied online, through mobile phone, or on social networks), and (d) sexual (unwanted sexual advances/ comments). Item 5 asks about the nature of the bullying, with response options of (a) racial (because of your skin color, ethnicity, or religious background), (b) homophobic/transphobic (because of your sexuality or gender identity; being part of the LGBT* community), (c) gender (because you are a boy or a girl), (d) appearance (because of your body image, clothes, weight, etc.), and (e) disability (because of a disability or additional needs).

As clinical experiences suggest that many young transgender people describe going through a period in which they initially identified as gay, and both types of bullying (homophobic and transphobic) may be experienced in a connected way, they can be difficult to differentiate from one another. Thus, the questionnaire asked about homophobic and transphobic bullying together as one item. For items 2-5, participants could select as many responses as were appropriate. Participants were also asked whether bullying occurred by more than one person (yes/no; item 6), whether they were able to tell anyone (yes/no; item 7) and if so, who they told (parent, teacher, family member, friend, other; item 8). The final question (item 9) presented a list of effects on wellbeing and participants were asked to indicate whether they felt that the bullying they experienced had affected them in any of the following ways: engaging in self-harm, experiencing suicidal thoughts, feeling depressed, feeling anxious, poor family relationships, feeling withdrawn, feeling angry, poor school work, lack of friendships, low self-esteem, and poor social life. Participants could select as many responses as were applicable.

\section{Data analysis}

All data were tabulated and analyzed in SPSS $22 .{ }^{54}$ Participants were allocated to groups according to reported bullying experiences (bullied/not bullied) and birth-assigned sex (male/female). The majority of the analyses were conducted on frequency data related to reported experiences of bullying (occurrence, location, help seeking, type, nature, and effects on wellbeing) and so were analyzed by chi-square test. As the experiences of bullying, particularly homophobic/ transphobic bullying, could have been affected by whether a person was out or had socially transitioned, data related to the frequency of reporting having experienced bullying and the nature of bullying experiences were also analyzed according to these categories (out vs. not out; socially transitioned vs. not socially transitioned). For the analyses assessing anxiety and depression, Shapiro-Wilk tests revealed that the data for both were non-normally distributed (anxiety: $W=0.972, p<0.001$; depression: $W=0.967, p<0.001)$. As a result, differences between groups were compared using Mann-Whitney $U$ tests. The significance level for all analyses was set at $p<0.05$.

\section{Results \\ Participant characteristics}

Three hundred and six participants aged 16-25 years were invited to take part in the study. Of these, $32(10.5 \%)$ 
declined and $274(89.5 \%)$ agreed. The majority of participants were White British $(n=263,96 \%)$. Data on disability were not collected. The mean age of those participating was 19.38 years $(\mathrm{SD}=2.55)$ and the modal age was 17 years old $(n=95,34.7 \%)$. There were $179(65.3 \%)$ birthassigned females and 95 (34.7\%) birth-assigned males. Information regarding gender identity indicated that 164 (59.9\%) participants identified as men, $77(28.1 \%)$ identified as women, $8(2.9 \%)$ identified as partly both, $6(2.2 \%)$ identified as neither, $8(2.9 \%)$ identified as other, $4(1.5 \%)$ did not know, and no response was available for 7 (2.6\%) participants. Due to the variation in gender identity, sex assigned at birth was used in this study.

In relation to coming out, 233 (85.0\%) participants indicated that they had come out and the mean age at which coming out occurred was 16.25 years $(\mathrm{SD}=3.28$, range 6-25 years). Being out was more common for birth-assigned females (93.9\% out vs. $6.1 \%$ not out) compared with birthassigned males $\left[68.4 \%\right.$ out vs. $31.6 \%$ not out; $\chi^{2}(1)=31.55$, $p<0.001]$. In terms of social transitioning, just over half $(n=157,57.3 \%)$ of participants indicated that they had socially transitioned by the time the assessment took place and the mean age of social transitioning was 17.08 years $(\mathrm{SD}=2.92$, range $8-25$ years). Birth-assigned females were more likely to have socially transitioned than not $(63.6 \%$ vs. 36.4\%), whereas the opposite was true for birth-assigned males $\left[36.0 \%\right.$ transitioned vs. $64.0 \%$ not; $\chi^{2}(1)=13.72$, $p<0.001]$. There was no significant difference in the age of those who indicated that they had (median $=18$, mean $=$ $19.23, \mathrm{SD}=2.58)$ versus had not $($ median $=19$, mean $=19.57$, $\mathrm{SD}=2.51)$ socially transitioned by their first assessment appointment $(U=8324, p=0.174)$. However, there was a significant difference in age according to being out, with those who were not out being significantly older $($ median $=20$, mean $=$ $20.17, \mathrm{SD}=2.31)$ than those who were out (median $=18$, mean $=19.24, \mathrm{SD}=2.57 ; U=3554, p=0.007)$.

\section{Characteristics of the bullied participants}

As shown in Table 1, of the 274 participants in the sample, $86.5 \%(n=237)$ reported having experienced bullying. There was a statistically significantly higher number of people who reported having experienced bullying than those who reported not having experienced bullying $\left[\chi^{2}(1)=145.985\right.$, $p<0.001]$. Birth-assigned females more often reported being bullied compared with birth-assigned males $[n=162$, $90.5 \%$ vs. $\left.n=75,78.9 \% ; \chi^{2}(1)=31.937, p<0.001\right]$. Birthassigned females who reported having experienced bullying were also significantly younger $($ median $=17$, mean $=18.72$, $\mathrm{SD}=2.36$ ) than birth-assigned males who reported having experienced bullying $($ median $=20$, mean $=20.6, S D=2.57$;
$U=8794, p<0.001$ ). Only 230 of the 237 participants who reported having experienced bullying answered the question regarding when bullying had occurred. For over half of the participants, this was 2 or more years ago $(n=137,59.6 \%$; $1-2$ years ago, $n=50,21.7 \%$; $<12$ months ago, $n=43$, $18.7 \%)$.

Out status, transition status, birth-assigned sex, and bullying. Table 1 shows that the majority of the 237 participants who indicated that they had experienced bullying were out by the time they were assessed $(n=203,85.7 \%)$ and just over half $(n=130,54.9 \%)$ indicated that they had socially transitioned. As the increased frequency of reporting bullying by birth-assigned females could have been influenced by differences in out/transition status, the analysis was repeated twice, only including those who were (1) socially transitioned $(n=130)$, or (2) out $(n=203)$ at the time of assessment. The first analysis showed that individuals who were socially transitioned were no more likely to report having experienced bullying than those who were not socially transitioned $\left[\chi^{2}(1)=2.232, p=0.135\right]$, but that birth-assigned females who were socially transitioned were more likely to report bullying $(n=103,63.6 \%)$ than socially transitioned birthassigned males $\left[n=27,36.0 \% ; \chi^{2}(1)=15.747, p<0.001\right]$. The second analysis showed that individuals who were out were more likely to report having experienced bullying $\left[\chi^{2}(1)=120.511, p<0.001\right]$ than those who were not out, and that out birth-assigned females $(n=153,94.4 \%)$ were more likely to report having experienced bullying than their out male birth-assigned counterparts $[n=50,66.7 \%$; $\left.\chi^{2}(1)=32.192, p<0.001\right]$. This confirms that independent of their out/social transition status, birth-assigned females were at a higher risk of being bullied than birth-assigned males.

\section{Where bullying occurred}

The majority of bullied participants $(n=221,93.2 \%)$ were highly likely to report having been bullied by more than one person. All but one of the participants who reported being bullied answered the question about where bullying occurred $(n=236)$ (Table 2). Analysis of the frequency with which participants reported that bullying occurred in different places found that bullying was significantly likely to occur at school $(n=217,91.9 \%)$. Bullying in other outside places $(n=87,36.9 \%)$ and online $(n=52,22.0 \%)$ was also reported but was significantly less common. Reporting being bullied at college/university $(n=46,19.5 \%)$ and work $(n=16$, $6.8 \%$ ) was much lower, mostly reflecting the age of the participants (i.e., not yet at work/university). Reporting being bullied at home was uncommon $(n=10,4.2 \%)$. The study did not find significant differences between sex assigned at birth and whether bullying was perpetrated by more than

Table 1. Frequency of Participants Reporting Having Experienced Bullying, Overall and by Social Transition or Out Status

\begin{tabular}{lccc}
\hline & $\begin{array}{c}\text { All }(\mathrm{N}=274) \\
\mathrm{n}(\%)\end{array}$ & $\begin{array}{c}\text { Birth-assigned males }(\mathrm{N}=95) \\
\mathrm{n}(\%)\end{array}$ & $\begin{array}{c}\text { Birth-assigned females }(\mathrm{N}=179) \\
\mathrm{n}(\%)\end{array}$ \\
\hline Bullied & $237(86.5)^{* *}$ & $75(78.9)^{* *}$ & $162(90.5)^{* *}$ \\
Socially transitioned and bullied & $130(54.9)$ & $27(36.0)^{* *}$ & $103(63 .)^{* *}$ \\
Out and bullied & $203(85.7)^{* *}$ & $50(66.7)^{* *}$ & $153(94.4)^{* *}$ \\
\hline
\end{tabular}

$* * p<0.001$. 


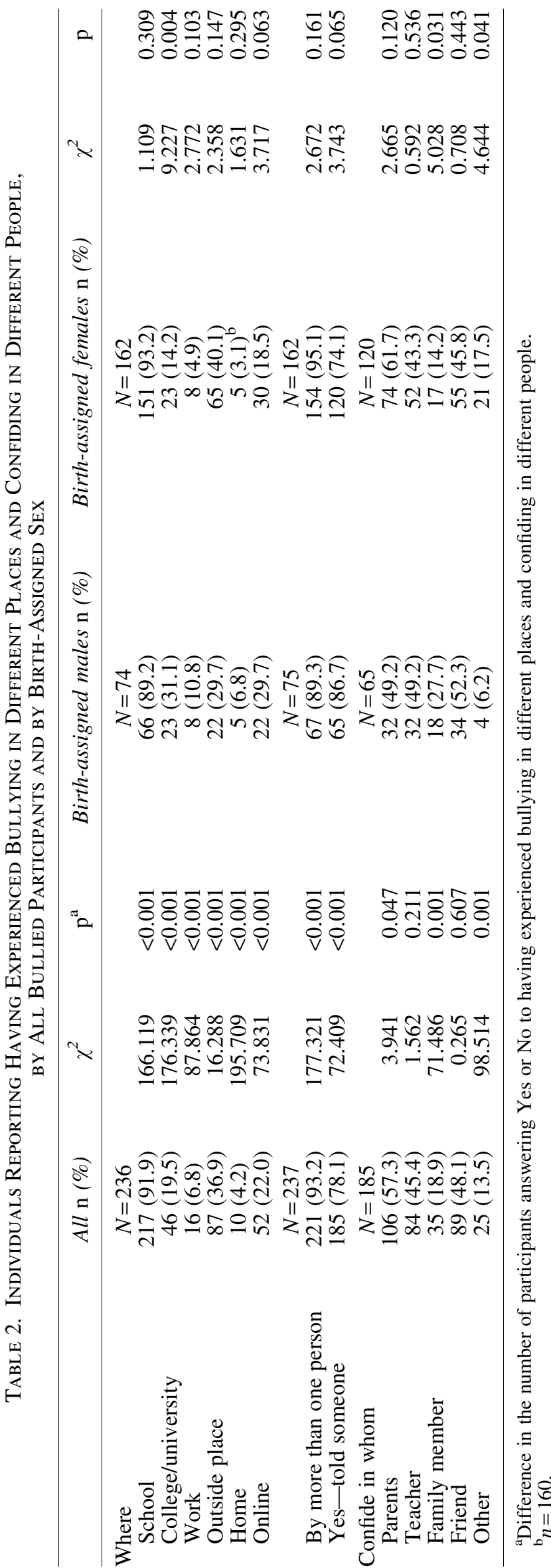

one person, nor being bullied at school, at work, outside, at home, or online.

\section{Asking for help}

Of the participants who reported being bullied $(n=237)$, the majority ( $n=185,78.1 \%$ ) stated that they told someone (Table 2). Parents were significantly likely to be told $(n=106,57.3 \%)$ followed by friends $(n=89,48.1 \%, n s)$ and teachers $(n=84,45.4 \%, n s)$. Other family members and "others" were significantly least likely to be confided in by the participants. There was a significant association between sex assigned at birth and seeking help (or not) from other family members and others. Specifically, birthassigned females $(n=17,14.2 \%)$ were less likely to report asking for help from other family members than birthassigned males $(n=18,27.7 \%)$, but more likely to report requesting help from "others" $(n=21,17.5 \%$ vs. $n=4$, $6.2 \%)$.

\section{Type of bullying}

In total, 233 participants answered questions about the type of bullying that they experienced (Table 3). Bullying was reported in all categories. Of these, name calling was significantly frequently reported $(n=223,95.7 \%)$, whereas physical $(n=86,36.9 \%)$, sexual $(n=68,29.2 \%)$, and cyber bullying $(n=61,26.2 \%)$ were significantly less common. Social bullying ( $n=120,51.1 \%)$ was reported by approximately half of the participants. No significant associations were found between any of the types of bullying and sex assigned at birth.

\section{Nature of bullying}

In total, 234 participants answered questions about the nature of the bullying that they experienced (Table 3). Bullying that was based on appearance $(n=189,80.8 \%)$ or was homophobic/transphobic ( $n=186,79.5 \%)$ was significantly frequently reported. Gender-based comments were relatively common $(n=111,47.4 \%)$, whereas racial and disabilitybased comments were least common, reflecting the lack of diversity in the sample. The nature of bullying reported most often by birth-assigned females was appearance-related bullying ( $n=144,89.4 \%)$ followed by homophobic/transphobic bullying ( $n=136,84.5 \%)$. These were also the most common to be reported by birth-assigned males, but to a significantly less extent ( $n=45,61.6 \%$ and $n=50,68.5 \%$, respectively). Gender-based bullying was significantly more frequently reported by birth-assigned females ( $n=87,54 \%$ vs. $n=24$, $32.9 \%)$.

Out status, transition status, birth-assigned sex, and nature of bullying. Within the socially transitioned group, homophobic/transphobic bullying was reported most frequently $(n=112,86.2 \%)$ and was significantly more common than in the nontransitioned group $(n=74,71.2 \%)$ (Table 4$)$. The nature of bullying that was reported the next most often was appearance-related bullying $(n=107,82.3 \%)$, which was similarly common in the nontransitioned group $(n=82$, $78.8 \%$ ). Conversely, gender-based bullying was more likely to be reported by the group that had not socially transitioned $(n=62,59.6 \%)$ compared with the socially transitioned 


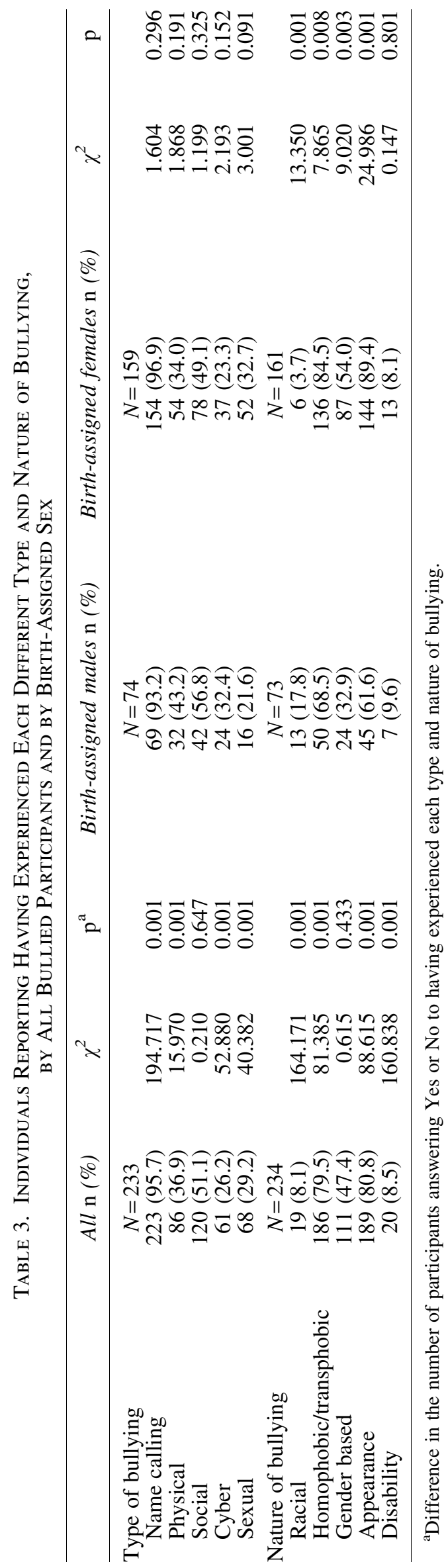

group ( $n=49,37.7 \%)$. Birth-assigned females within the socially transitioned group were more likely to report appearance-related bullying than birth-assigned males $\left[n=92,89.3 \%\right.$ vs. $\left.n=15,55.6 \% ; \chi^{2}(1)=16.748, p<0.001\right]$, but no other differences were significant.

For those who were out, appearance-related bullying was reported most frequently $(n=170,84.6 \%)$, and this was reported significantly more often compared with those who were not out $(n=19,57.6 \%)$ (Table 4$)$. The next most frequent nature of bullying reported by out participants was homophobic/transphobic bullying and this nature of bullying was the most commonly reported by the not out individuals ( $n=162,80.6 \%$ vs. $n=24,72.7 \%$ ). Gender-based bullying was reported by approximately half of all participants in each group (out; $n=94,46.8 \%$ : not out; $17,51.5 \%$ ) and, therefore, there were no significant differences in the likelihood of reporting this nature of bullying.

Out birth-assigned females mostly reported experiencing appearance-related bullying $(n=136,89.5 \%)$, which was reported significantly more often than by birth-assigned males $\left[n=34,69.4 \% ; \chi^{2}(1)=11.461, p=0.002\right]$. They also often reported experiencing homophobic/transphobic bullying $(n=128,84.2 \%)$, which was reported significantly more often than by birth-assigned males [ $n=34,69.4 \%$; $\chi^{2}(1)=5.206, p=0.036$ ], and just over half reported genderbased bullying compared with a quarter of birth-assigned males $\left[n=81,53.3 \%\right.$ vs. $n=13,26.5 \% ; \chi^{2}(1)=10.658$, $p=0.002]$. Racial $\left[\chi^{2}(1)=2.06, n s\right]$ and disability-based $\left[\chi^{2}(1)=0.45, n s\right]$ bullying was equally infrequently reported by both birth-assigned sex groups, again likely reflecting the lack of diversity within the group.

\section{Self-reported effects of bullying on wellbeing}

Table 5 shows the frequency of reported effects of bullying on wellbeing, as assessed by the Transgender Bullying Questionnaire. The most frequently cited effect was on self-esteem $(n=196,82.7 \%)$. In addition, frequently and significantly endorsed were effects on anxiety $(n=162,68.4 \%)$ and depression $(n=139,58.6 \%)$. Approximately half of the participants reported the following adverse effects of bullying: poor social life, feeling withdrawn, feeling angry, and lack of friends. Significantly less likely to be reported was any effect on family relationships, school work, or experiences of selfharm or suicidal thoughts. However, when analyzing birthassigned sex, birth-assigned females were more likely than birth-assigned males to indicate that bullying had affected family relationships $(n=51,31.5 \%$ vs. $n=9,12 \%)$ and social life $(n=92,56.8 \%$ vs. $n=31,41.3 \%)$. All other differences were nonsignificant.

\section{Association with anxiety and depression at assessment}

Mann-Whitney $U$ tests performed on the HADS responses showed that significantly more anxiety was reported by those who reported experiencing bullying (median $=12.00$, $\mathrm{SD}=4.209)$ than those who reported that they had not experienced bullying (median $=9.00, \mathrm{SD}=5.324 ; U=3122.5$, $p=0.005$ ), but that the difference in depression failed to reach significance $($ median $=7.00, \quad \mathrm{SD}=3.7$ and medi$\mathrm{an}=6.00, \mathrm{SD}=3.079$, respectively; $U=3537.5, p=0.058$ ). No differences were found in anxiety between birth-assigned females $($ median $=12.00, \mathrm{SD}=4.505)$ and birth-assigned 

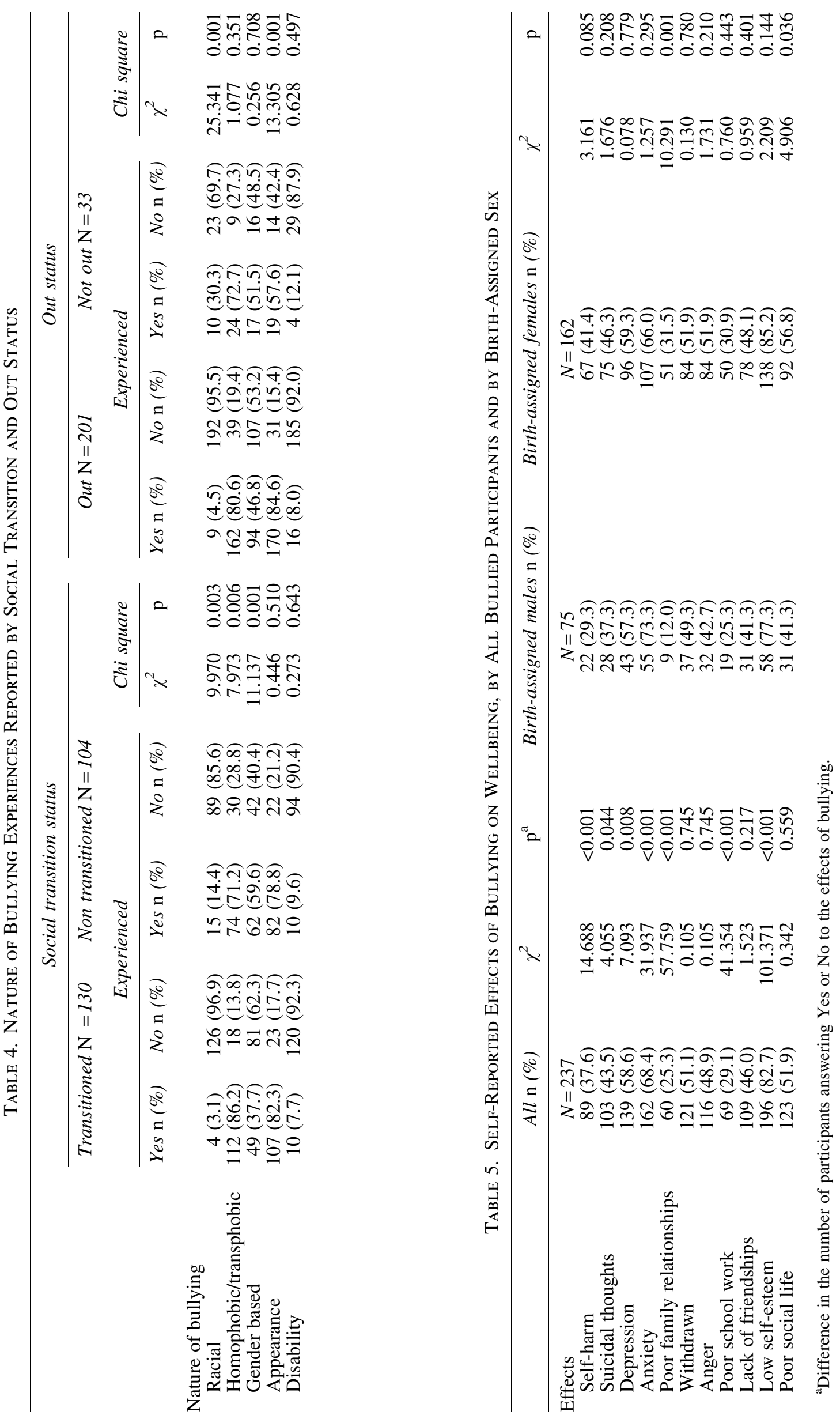
males (median $=10.00, \mathrm{SD}=4.345 ; U=8415.5, p=0.889$ ) or in depression between these groups (median $=7.00, \mathrm{SD}=3.748$, and median $=7.00, \mathrm{SD}=3.654$ respectively; $U=7707.5$, $p=0.201)$.

\section{Discussion}

This study explored the experiences of bullying reported by young people presenting for their first appointment at a transgender health service in the United Kingdom and how these experiences related to their wellbeing and levels of anxiety and depression. The study found that within these TGD youth, rates of bullying were very high, with the majority reporting having experienced bullying (86.5\%), with name calling being extremely common (reported by $96 \%$ of the bullied participants). This is somewhat higher than many recently reported rates of bullying in the general population (22\% in 12-20-year olds ${ }^{55}$ ) and in LGB youth (55\% in 2012 , and $65 \%$ in $2007^{44,56}$ ), suggesting that TGD youth are at increased risk for bullying compared with sexual minority youth. It is also higher than in the most recent Stonewall reports of transgender youth $\left(64 \%\right.$ in $\left.2017^{44}\right)$, which may reflect differences in the experiences of youth who have already accessed health care.

Within the bullied group, birth-assigned females reported having experienced bullying more often than did birthassigned males. This finding was not in line with our hypothesis that birth-assigned males may experience more bullying due to society's difficulty in accepting feminine boys. ${ }^{45,46}$ Although this may reflect changing attitudes toward masculinity, ${ }^{57}$ this does not negate the fact that the high prevalence of bullying suggests that it is still very much driven by heteronormative norms.$^{58}$ However, it is consistent with research that has shown that bullying is more often experienced by females (both lesbian and heterosexual) than males, ${ }^{59}$ and that females are more likely to experience more indirect bullying and victimization, ${ }^{60}$ including backbiting, social exclusion, and manipulations of social structures to cause pain. It may also reflect deeply rooted differences in the stigma related to "being bullied," with birth-assigned males less likely to report this due to perceptions of weakness. ${ }^{61}$

Overall, bullying was most frequently appearance related or homophobic/transphobic in content, particularly among birth-assigned females. Experiencing these two types of bullying may contribute to the elevated levels of distress described for TGD individuals assigned female at birth. ${ }^{62,63}$ Birthassigned females also reported experiencing sexual bullying more often, but physical bullying less often than did birthassigned males, although the differences were not statistically significant. These findings seem to suggest that birth-assigned females are at an increased risk for bullying on multiple levels, which are all seemingly related to gender norms of appearance and sexuality. This may possibly reflect the prevalent misogynistic discrimination and bullying to which cisgender females are subjected. ${ }^{64}$ The possibility that bullying is highly gender driven, influencing the type of bullying that is engaged in/or experienced ${ }^{65}$ warrants further study, as does the influence of the gender of the perpetrator.

Bullying was also influenced by out status, being more commonly reported by those who were out. However, it was not influenced by social transition status, being equally common in those who had and had not socially transitioned.
Appearance-related bullying was reported significantly more often by out individuals, whereas homophobic/transphobic bullying was reported more often by socially transitioned individuals. In addition, socially transitioned individuals were less likely to report experiencing gender-based bullying than their nontransitioned counterparts. Again, within each group, birth-assigned females were more at risk. These findings suggest that being out may attract bullying related to how one presents oneself and that bullying may move away from appearance and not conforming to gender norms (gender-based bullying) to more explicit transphobia when a social transition is made. This also suggests that gender-based bullying is likely to remain high for those who do not identify on the gender binary. Indeed, as nonbinary people become more visible in society, ${ }^{66-68}$ gender-based bullying is likely to increase. This reflects a potentially negative impact of increasing awareness of diversity of gender identities, in that it can create a further basis for bullying. ${ }^{69}$

The majority of bullying was found to occur in school and be perpetrated by more than one person. Although it was encouraging that $78 \%$ of those who reported being bullied had confided in someone, this was predominantly parents. This suggests that the school environment is not regarded as supportive and schools should be doing more to help reduce the bullying of TGD youth. ${ }^{70}$ Schools have a very influential role to play in how young people view gender roles and identi$\mathrm{ty}^{37,71}$ and are as influential as family in supporting engagement in and satisfaction with school. ${ }^{72}$ Studies have found that teachers themselves might engage in transphobic bullying or fail to intervene when they witness this bullying. ${ }^{41,44}$ As a result, TGD students may internalize more stigma and discrimination than their LGB counterparts, ${ }^{63,73}$ as students in the United Kingdom report that their schools teach that homophobic bullying is wrong, but do not similarly teach that transphobic bullying is wrong. ${ }^{44}$ In this regard, the Fundamental Rights Agency - the European Union's center of human rights expertise tasked with conducting research, increasing awareness, and developing and promoting policy to protect the fundamental right to dignity-encourages schools to adopt general antibullying policies that include transgender issues. ${ }^{74}$

When assessing the reported effects of bullying, the majority of individuals indicated that their self-esteem had been affected. This is not surprising as bullying erodes sense of belonging, and ostracism has been linked to reduced self-esteem and be similar to physical pain. ${ }^{75}$ Birth-assigned sex influenced the reported effect on family relationships and social life, with birth-assigned females being more likely to indicate negative effects in these areas. Why this is the case is unclear. However, it may be that although bullying in school was common for both birth-assigned males and females, and mainly consisted of name calling, the difference in the context may be important. Birth-assigned females may be experiencing more indirect bullying ${ }^{62}$ that affects social functioning and, therefore, has a greater impact on social life. Indeed, transgender youth have been found to report problems with school climate and attendance, even if grades do not suffer ${ }^{76}$ suggesting the importance of social life within this context. This also may then cascade to influence family relationships.

In terms of the association of bullying with anxiety and depression measured with a clinically validated tool, bullied 
individuals had significantly higher levels of anxiety symptomatology, but not depression, than those who had not been bullied. This was the same for both birth-assigned sexes. High levels of anxiety have been found in transgender people attending health services, ${ }^{8,9}$ and these findings suggest that bullying could be part of the etiology of anxiety experienced by this population. Although there was no increased reporting of risk of self-harm and suicidality, lifetime exposure to trans-related victimization has been shown to be related to suicidality, ${ }^{17,77}$ and so it is important to note effects on wellbeing from a young age.

\section{Strengths and limitations}

A merit of this study is that it has gone beyond a simple survey of all LGBT youth and has explored bullying of TGD youth more systematically. It was conducted with a sample of young TGD people attending a national transgender health service who are assumed to be relatively homogeneous. However, we note that we do not know when bullying occurred in relation to coming out/social transitioning. Furthermore, the assessment of being out/having socially transitioned with a simple dichotomous yes/no question may be too simplistic and lack precision to report reliably on individuals' experiences. For example, a person may be out in some circumstances but not in others, and social transition can happen gradually and be dependent on context. We also do not know whether some of the participants may have already started to self-medicate with hormones. ${ }^{78,79}$ As gender-affirming hormone use is associated with improved mental health, ${ }^{53,80-82}$ some of the participants may have reported greater wellbeing as a result of taking hormones, and thus the effects of bullying on anxiety and depression may be underestimated. Future studies should control for medical and psychiatric history.

In addition, this study only recruited individuals who were in contact with a transgender health service and should not be considered to be representative of all TGD youth. There may be differences between those who are and are not attending a service that are important in relation to mental health. For example, those not in contact with a service may experience less bullying but may be living with more internal stressors (e.g., fear, anxiety, and anticipated family rejection). ${ }^{83}$ Conversely, our bullied participants may be experiencing better mental health as a result of being in contact with a service and possibly an imminent start to the process of medical transition, or indeed may be underreporting difficulties due to concerns over their acceptance for medical transition.

Finally, the possibility that TGD youth who experience homophobic bullying do so in different ways to LGB youth needs to be explored further. Indeed, some TGD youth report initially identifying as lesbian, gay, or bisexual and experience homophobic bullying, before later identifying as transgender. Thus, they may experience bullying on multiple intersecting levels. ${ }^{84}$ It should be noted that our sample was racially homogeneous and is, therefore, not representative of those who have multiple stigmatized identities. Future research should seek to explore in more depth the different ways in which young TGD people experience bullying and any associated factors, such as transition status and early sexuality identification, as well as ethnicity and disability, which could contribute to the nature and type of bullying experienced.

\section{Conclusion}

The results of this study highlight the high levels of bullying that TGD young people are subjected to and the effect of bullying on decreased psychological wellbeing and aspects of functioning. Schools, where most bullying occurs, have a significant role to play in supporting TGD youth, and future studies should investigate the efficacy of educational programs that can teach acceptance and nontolerance of bullying. Clinical practice needs to incorporate the investigation of bullying experiences into patient care and acknowledge the role of bullying in problems with anxiety and self-esteem to best serve help-seeking TGD youth.

\section{Author Disclosure Statement}

No competing financial interests exist.

\section{References}

1. Van Caenegem E, Wierckx K, Elaut E, et al.: Prevalence of gender nonconformity in Flanders, Belgium. Arch Sex Behav 2015;44:1281-1287.

2. Fielding J, Bass C: Individuals seeking gender reassignment: Marked increase in demand for services. BJPsych Bull 2018;42:206-210.

3. Zucker KJ, Wood H, Wasserman L, et al.: Increasing referrals for gender dysphoria. J Adolesc Health 2016;58:693694.

4. Wiepjes CM, Nota NM, de Blok CJM, et al.: The Amsterdam Cohort of Gender Dysphoria Study (1972-2015): Trends in prevalence, treatment, and regrets. J Sex Med 2018;15:582-590.

5. Beek TF, Kreukels BP, Cohen-Kettenis PT, Steensma TD: Partial gender requests and underlying motives of applicants for gender affirming interventions. J Sex Med 2015;12: 2201-2205.

6. Wylie K, Barrett J, Besser M, et al.: Good practice guidelines for the assessment and treatment of adults with gender dysphoria. Sex Relat Ther 2014;29:154-214.

7. Bockting WO, Miner MH, Swinburne Romine RE, et al.: Stigma, mental health, and resilience in an online sample of the US transgender population. Am J Public Health 2013;103:943-951.

8. Bouman WP, Claes L, Brewin N, et al.: Transgender and anxiety: A comparative study between transgender people and the general population. Int J Transgend 2017;18:16-26.

9. Millet N, Longworth J, Arcelus J: Prevalence of anxiety symptoms and disorders in the transgender population: A systematic review of the literature. Int $\mathbf{J}$ Transgend 2017; $18: 27-38$.

10. Witcomb GL, Bouman WP, Claes L, et al.: Levels of depression in transgender people and its predictors: Results of a large matched control study with transgender people accessing clinical services. J Affect Dis 2018;235:308-315.

11. Warren JC, Smalley KB, Barefoot KN: Psychological wellbeing among transgender and genderqueer individuals. Int $\mathbf{J}$ Transgend 2016;17:114-123.

12. Davey A, Bouman WP, Arcelus J, Meyer C: Social support and psychological wellbeing in gender dysphoria: A comparison of patients with matched controls. J Sex Med 2014;11:2976-2985.

13. Marshall E, Claes L, Bouman WP, et al.: Non-suicidal selfinjury and suicidality in trans people: A systematic review of the literature. Int Rev Psychiatry 2016;28:58-69. 
14. Arcelus J, Claes L, Witcomb GL, et al.: Risk factors for nonsuicidal self-injury among trans youth. J Sex Med 2016;13: 402-412.

15. van de Grift TC, Cohen-Kettenis PT, Steensma TD, et al.: Body satisfaction and physical appearance in gender dysphoria. Arch Sex Behav 2016;45:575-585.

16. Witcomb GL, Bouman WP, Brewin N, et al.: Body image dissatisfaction and eating-related psychopathology in trans individuals: A matched control study. Eur Eat Disord Rev 2015;23:287-293.

17. Rimes KA, Goodship N, Ussher G, et al.: Non-binary and binary transgender youth: Comparison of mental health, selfharm, suicidality, substance use and victimization experiences. Int J Transgend 2017; DOI: 10.1080/15532739.2017.1370627.

18. Thorne N, Witcomb GL, Nieder T, et al.: A comparison of mental health symptomatology and levels of social support in young treatment seeking transgender individuals who identify as binary and non-binary. Int J Transgend 2018; DOI: $10.1080 / 15532739.2018 .1452660$.

19. Claes L, Bouman WP, Witcomb G, et al.: Non-suicidal selfinjury in trans people: Associations with psychological symptoms, victimization, interpersonal functioning, and perceived social support. J Sex Med 2015;12:168-179.

20. Steensma TD, McGuire JK, Kreukels BP, et al.: Factors associated with desistence and persistence of childhood gender dysphoria: A quantitative follow-up study. J Am Acad Child Adolesc Psychiatry 2013;52:582-590.

21. Kroger J: Identity Development: Adolescence Through Adulthood. Thousand Oaks, CA: Sage Publications, Inc., 2006.

22. Jones BA, Arcelus J, Bouman WP, Haycraft E: Barriers and facilitators of physical activity and sport participation among young transgender adults who are medically transitioning. Int J Transgend 2017;18:227-238.

23. Jones BA, Arcelus J, Bouman WP, Haycraft E: Sport and transgender people: A systematic review of the literature relating to sport participation and competitive sport policies. Sports Med 2017;47:701-716.

24. Anderson E, Travers A, editors: Transgender Athletes in Competitive Sport. New York: Routledge, 2017.

25. Collier KL, van Beusekom G, Bos HM, Sandfort TG: Sexual orientation and gender identity/expression related peer victimization in adolescence: A systematic review of associated psychosocial and health outcomes. J Sex Res 2013;50: 299-317.

26. Pflum S, Testa R, Balsam K, et al.: Social support, trans community connectedness, and mental health symptoms among transgender and gender nonconforming adults. Psychol Sex Orientat Gend Divers 2015;2:281-286.

27. Williams KL, Galliher RV: Predicting depression and selfesteem from social connectedness, support, and competence. J Soc Clin Psychol 2006;25:855-874.

28. Austin A, Goodman R: The impact of social connectedness and internalized transphobic stigma on self-esteem among transgender and gender non-conforming adults. J Homosex 2017;64:825-841.

29. Skues JL, Cunningham EG, Pokharel T: The influence of bullying behaviours on sense of school connectedness, motivation and self-esteem. J Psychol Couns Schools 2005;15: $17-26$.

30. Anti-Bullying Alliance: 2018. Available at www.antibullyingalliance.org.uk Accessed December 12, 2018.

31. Juvonen J, Graham S: Bullying in schools: The power of bullies and the plight of victims. Annu Rev Psychol 2014; 65:159-185.
32. Idsoe T, Dyregrov A, Idsoe EC: Bullying and PTSD symptoms. J Abnorm Child Psychol 2012;40:901-911.

33. Takizawa R, Maughan B, Arseneault L: Adult health outcomes of childhood bullying victimization: Evidence from a fivedecade longitudinal British birth cohort. Am J Psychiatry 2014;171:777-784.

34. Reisner SL, Vetters R, Leclerc M, et al.: Mental health of transgender youth in care at an adolescent urban community health center: A matched retrospective cohort study. J Adolesc Health 2015;56:274-279.

35. Veale JF, Watson RJ, Peter T, Saewyc EM: Mental health disparities among Canadian transgender youth. J Adolesc Health 2017;60:44-49.

36. Connolly MD, Zervos MJ, Barone CJ 2nd, et al.: The mental health of transgender youth: Advances in understanding. J Adolesc Health 2016;59:489-495.

37. Bartholomaeus C, Riggs DW: Whole-of-school approaches to supporting transgender students, staff, and parents. Int $\mathbf{J}$ Transgend 2017;18:361-366.

38. Clark TC, Lucassen MF, Bullen P, et al.: The health and well-being of transgender high school students: Results from the New Zealand adolescent health survey (Youth'12). J Adolesc Health 2014;55:93-99.

39. Gordon AR, Conron KJ, Calzo JP, et al.: Nonconforming gender expression is a predictor of bullying and violence victimization among high school students in four U.S. school districts. J Adolesc Health 2016;58:S1-S2.

40. Mitchell KJ, Ybarra ML, Korchmaros JD: Sexual harassment among adolescents of different sexual orientations and gender identities. Child Abuse Negl 2014;38:280-295.

41. Whittle S, Turner L, Al-Alami M: Engendered penalties: Transgender and transsexual people's experiences of inequality and discrimination. 2007. Available at www.pfc .org.uk/pdf/EngenderedPenalties.pdf Accessed June 19, 2018.

42. Jackman KB, Dolezal C, Bockting WO: Generational differences in internalized transnegativity and psychological distress among feminine spectrum transgender people. LGBT Health 2018;5:54-60.

43. Savin-Williams RC: The New Gay Teenager. Cambridge, MA: Harvard University Press, 2005.

44. Bradlow J, Bartram F, Guasp A, Jadva V: School report: The experiences of lesbian, gay, bi and trans young people in Britain's schools in 2017. London: Stonewall, 2017.

45. Devís-Devís J, Pereira-García S, López-Cañada E, et al.: Looking back into trans persons' experiences in heteronormative secondary physical education contexts. Phys Educ Sport Pediatr 2018;23:103-116.

46. Connell RW: Masculinities. Berkeley and Los Angeles, CA: University of California Press, 2005.

47. UNESCO: By youth, with youth, for youth: Welcome to the UNESCO Youth Programme! 2017. Available at www .unesco.org/new/en/social-and-human-sciences/themes/ youth Accessed December 11, 2018.

48. Beek TF, Cohen-Kettenis PT, Bouman WP, et al.: Gender incongruence of adolescence and adulthood: Acceptability and clinical utility of the World Health Organization's proposed ICD-11 criteria. PLoS One 2016;11:e0160066.

49. Beek TF, Cohen-Kettenis PT, Bouman WP, et al.: Gender incongruence of childhood: Clinical utility and stakeholder agreement with the World Health Organization's proposed ICD-11 criteria. PloS One 2017;12:e0168522.

50. Zigmond AS, Snaith RP: The hospital anxiety and depression scale. Acta Psychiatr Scand 1983;67:361-370. 
51. Bjelland I, Dahl AA, Haug TT, Neckelmann D: The validity of the Hospital Anxiety and Depression Scale. An updated literature review. J Psychosom Res 2002;52:69-77.

52. White D, Leach C, Sims R, et al.: Validation of the Hospital Anxiety and Depression Scale for use with adolescents. Br J Psychiatry 1999;175:452-454.

53. Gómez-Gil E, Zubiaurre-Elorza L, Esteva I, et al.: Hormone-treated transsexuals report less social distress, anxiety, and depression. Psychoneuroendocrinology 2012; 37:662-670.

54. IBM Corporation: IBM SPSS Statistics for Windows. Version 22.0. Armonk, NY: IBM Corporation, 2013.

55. Ditch the Label: The Annual Bullying Survey 2018: The Annual Benchmark of Bullying in the United Kingdom. 2018. Available at https://www.ditchthelabel.org/wp-content/ uploads/2018/06/The-Annual-Bullying-Survey-2018-2.pdf Accessed December 11, 2018.

56. White AJ, Magrath R, Thomas B: The experiences of lesbian, gay and bisexual students and staff at a Further Education college in South East England. Brit Educ Res J 2018; 44:480-495.

57. Anderson E, McCormack M: Inclusive masculinity theory: Overview, reflection and refinement. J Gend Stud 2018; 27:547-561.

58. Carrera-Fernández MV, Lameiras-Fernández M, RodríguezCastro Y: Performing intelligible genders through violence: Bullying as gender practice and heteronormative control. Gend Educ 2018;30:341-359.

59. Kahle L: Are sexual minorities more at risk? Bullying victimization among lesbian, gay, bisexual, and questioning youth. J Interpers Violence 2017; DOI: 10.1177/0886260517718830.

60. Crick NR, Nelson DA, Morales JR, et al.: Relational victimization in childhood and adolescence: I hurt you through the grapevine. In: Peer Harassment in School: The Plight of the Vulnerable and Victimized. Edited by Juvonen J, Graham S. New York: The Guilford Press, 2001, pp 196-214.

61. Lai T, Kao G: Hit, robbed, and put down (but not bullied): Underreporting of bullying by minority and male students. J Youth Adolesc 2018;47:619-635.

62. Grossman AH, D'Augelli AR: Transgender youth: Invisible and vulnerable. J Homosex 2006;51:111-128.

63. Rood BA, Reisner SL, Surace FI, et al.: Expecting rejection: Understanding the minority stress experiences of transgender and gender-nonconforming individuals. Transgend Health 2016;1:151-164.

64. Mishna F, Schwan KJ, Birze A, et al.: Gendered and sexualized bullying and cyber bullying: Spotlighting girls and making boys invisible. Youth Soc 2018; https://doi.org/10 $.1177 / 0044118 X 18757150$

65. O'Brien C: Young people's comparisons of cross-gender and same-gender bullying in British secondary schools. Educ Res 2011;53:257-301.

66. Richards C, Bouman WP, Seal L, et al.: Non-binary or genderqueer genders. Int Rev Psychiatry 2016;28:95-102.

67. Richards C: Genderqueer and non-binary genders. In: The Transgender Handbook: A Guide for Transgender People, Their Families and Professionals (Human Sexuality). Edited by Bouman WP, Arcelus J. New York: Nova Science Publishers, 2017, pp 47-158.

68. Richards C, Bouman WP, Barker MJ, eds: Genderqueer and Non-Binary Genders. London: Palgrave Macmillan, 2018.

69. Veldhuis CB, Drabble L, Riggle ED, et al.: "I fear for my safety, but want to show bravery for others": Violence and discrimination concerns among transgender and gender- nonconforming individuals after the 2016 Presidential Election. Violence Gender 2018;5:26-36.

70. Espelage DL: Sexual orientation and gender identity in schools: A call for more research in school psychologyNo more excuses. J Sch Psychol 2016;54:5-8.

71. Shutts K, Kenward B, Falk H, et al.: Early preschool environments and gender: Effects of gender pedagogy in Sweden. J Exp Child Psychol 2017;162:1-17.

72. Gutiérrez M, Tomás JM, Romero I, Barrica JM: Perceived social support, school engagement and satisfaction with school. Rev Psicodidáct (English ed.) 2017;22:111-117.

73. Puckett JA, Levitt HM: Internalized stigma within sexual and gender minorities: Change strategies and clinical implications. J LGBT Issues Couns 2015;9:329-349.

74. European Union Agency for Fundamental Rights: EU LGBT survey-European Union lesbian, gay, bisexual and transgender survey-Results at a glance. 2013. Available at http://fra .europa.eu/en/publication/2013/eu-lgbt-survey-europeanunion-lesbian-gay-bisexual-and-transgender-survey-results Accessed December 14, 2018.

75. Williams KD: Ostracism: The kiss of social death. Soc Pers Psychol Compass 2007;1:236-247.

76. Day JK, Perez-Brumer A, Russell ST: Safe Schools? Transgender youth's school experiences and perceptions of school climate. J Youth Adolesc 2018;47:1731-1742.

77. Zeluf G, Dhejne C, Orre C, et al.: Targeted victimization and suicidality among trans people: A web-based survey. LGBT Health 2018;5:180-190.

78. Mepham NJ, Bouman WP, Arcelus J, et al.: People with gender dysphoria who self-prescribe cross-sex hormones: Prevalence, sources, and side effects knowledge. J Sex Med 2014;11:2995-3001.

79. Rotondi NK, Bauer GR, Scanlon K, et al.: Nonprescribed hormone use and self-performed surgeries: "do-it-yourself" transitions in transgender communities in Ontario, Canada. Am J Public Health 2013;103:1830-1836.

80. Bouman WP, Claes L, Marshall E, et al.: Sociodemographic variables, clinical features, and the role of preassessment cross-sex hormones in older trans people. J Sex Med 2016;13:711-719.

81. Owen-Smith AA, Gerth J, Sineath RC, et al.: Association between gender confirmation treatments and perceived gender congruence, body image satisfaction, and mental health in a cohort of transgender individuals. J Sex Med 2018;15: 591-600.

82. White Hughto JM, Reisner SL: A systematic review of the effects of hormone therapy on psychological functioning and quality of life in transgender individuals. Transgend Health 2016;1:21-31.

83. Catalpa JM, McGuire JK: Family boundary ambiguity among transgender youth. Fam Relat 2018;67:88-103.

84. Stoetzler M: From interacting systems to a system of divisions: The concept of society and the 'mutual constitution' of intersecting social divisions. Eur J Soc Theory 2016;20:455-472.

Address correspondence to: Gemma L. Witcomb, PhD School of Sport, Exercise and Health Sciences Loughborough University Loughborough LE11 3TU United Kingdom

E-mail: g.1.witcomb@lboro.ac.uk 